\title{
Evaluation of the impact of glycemic status on the progression of coronary artery calcification in asymptomatic individuals
}

\author{
Ki-Bum Won ${ }^{1,2}$, Donghee Han², Ji Hyun Lee², Sang-Eun Lee², Ji Min Sung ${ }^{2}$, Su-Yeon Choi³ , Eun Ju Chun ${ }^{4}$, \\ Sung Hak Park ${ }^{5}$, Hae-Won Han', Jidong Sung ${ }^{7}$, Hae Ok Jung ${ }^{8}$ and Hyuk-Jae Chang ${ }^{2,9^{*}}$ (D)
}

\begin{abstract}
Background: Data on the influence of glycemic status on the progression of coronary calcification, an important marker for future adverse cardiovascular events, are limited.

Methods: Data from the Korea Initiatives on Coronary Artery Calcification (KOICA) registry on 12,441 asymptomatic Korean adults ( $52 \pm 9$ years, $84.2 \%$ males) without previous history of coronary artery disease and stroke, who underwent serial coronary artery calcification (CAC) screening examinations, were included in this study. The median inter-scan period was 3.0 (2.0-4.8) years. All participants were categorized into three groups based on their glycemic status: normal $(n=6578)$, pre-diabetes $(n=4146)$, and diabetes $(n=1717)$. CAC progression was defined as a difference $\geq 2.5$ between the square roots $(\sqrt{ })$ of the baseline and follow-up CAC scores.

Results: The incidence of CAC progression was significantly different between the three groups (normal, 26.3\%; pre-diabetes, 30.9\%; and diabetes, 46.9\%; $\mathrm{p}<0.001)$. In the univariate logistic analysis, the risk of CAC progression was higher in the pre-diabetes (odds ratio [OR] 1.253; 95\% confidential interval [CI] 1.150-1.366) and diabetes (OR 2.471; $95 \% \mathrm{Cl} 2.215-2.758$ ) groups than in the normal group ( $p<0.001$, both). In the multivariate logistic analysis, the risk of CAC progression was not significantly different between the normal and pre-diabetes groups but was significantly higher in the diabetes group than in the normal group.
\end{abstract}

Conclusions: In asymptomatic subjects, diabetes had an incremental impact on CAC progression; however, prediabetes did not increase the risk of CAC progression after adjusting for confounding factors.

Keywords: Pre-diabetes, Diabetes, Coronary artery calcification

\section{Background}

Diabetes is one of the major causes of cardiovascular (CV) morbidity and mortality worldwide. Several metaanalyses have reported that diabetes increases the risk of developing coronary artery disease (CAD) two to threefold [1-4]. It is well-known that diabetes is associated with an increased risk of CAD after adjusting for other traditional CV risk factors. However, uncertainty remains

\footnotetext{
*Correspondence: hjchang@yuhs.ac

${ }^{9}$ Division of Cardiology, Severance Cardiovascular Hospital, Yonsei

University College of Medicine, Yonsei University Health System, 50-1

Yonsei-ro, Seodaemun-gu, Seoul 03722, South Korea

Full list of author information is available at the end of the article
}

as to whether a pre-diabetic condition is independently associated with the progression of coronary atherosclerosis $[5,6]$.

Coronary artery calcification (CAC) is associated with atherosclerotic burden and adverse $\mathrm{CV}$ clinical outcomes [7-10]. Furthermore, CAC progression is a powerful predictor of mortality over the baseline CAC score and traditional CV risk factors [11]. Therefore, this study aimed to explore the association between glycemic status and CAC progression in an asymptomatic Korean population using serial cardiac computed tomography (CT) scans. 


\section{Methods}

\section{Study population and design}

Data from the Korea Initiatives on Coronary Artery Calcification (KOICA) multicenter registry were analyzed. This is a retrospective, single ethnicity, multicenter observational registry in a self-referral setting for subjects who underwent health checkups at six health care centers in South Korea. A total of 93,707 subjects were enrolled in the KOICA registry from December 2012 to August 2016. Self-reported medical questionnaires were used to obtain information about medical history. All data were obtained during visits to each healthcare center. Among the 93,707 subjects from this registry, 12,441 , who underwent at least two CAC scan examinations with available glycemic status data, were included in this study. All participants were categorized into three groups based on their glycemic status: normal, pre-diabetes, and diabetes. Pre-diabetes was defined as a fasting plasma glucose (FPG) level of $100-125 \mathrm{mg} / \mathrm{dL}$ or hemoglobin A1c (HbA1c) levels of 5.7-6.4\% [12]. Diabetes was defined as either an FPG level of $\geq 126 \mathrm{mg} / \mathrm{dL}, \mathrm{HbA1c}$ level of $\geq 6.5 \%$, a referral diagnosis of diabetes, or currently receiving anti-diabetic treatment $[12,13]$.

Coronary artery calcification score was determined based on the scoring system previously described by Agatston et al. [14]. CAC progression was defined as a difference $\geq 2.5$ between the square roots $(\sqrt{ })$ of the baseline and follow-up CAC scores $(\Delta \sqrt{ }$ transformed CAC) [15]. The appropriate institutional review board committees of each healthcare center approved the study protocol. Information on the medical history of hypertension, diabetes, and smoking status for each subject was systematically collected. Height, weight, and blood pressure were measured during the healthcare center visits. All blood samples were obtained after a minimum of an $8 \mathrm{~h}$ fast and analyzed for triglyceride, high-density lipoprotein (HDL) cholesterol, low-density lipoprotein (LDL) cholesterol, and glucose levels. In all centers, a $\mathrm{CT}$ scan to assess CAC was performed using a $>16$ slice multi-detector CT scanner (Siemens 16-slice Sensation, Philips Brilliance 256 iCT, Philips Brilliance 40 channel MDCT, and GE 64-slice Lightspeed). All centers performed standard prospective or retrospective methods.

\section{Statistical analysis}

Continuous variables are expressed as mean \pm standard deviation. Categorical variables are presented as absolute values and proportions. To compare the characteristics of participants among the three glycemic groups, the one-way analysis of variance with Bonferroni's post hoc test or the Kruskal-Wallis test was used for continuous variables, as appropriate, and the Chi square test for categorical variables. Univariate logistic regression analysis was performed to identify the clinical factors significant for CAC progression. Subsequently, multivariate logistic regression analysis was used to identify the independent impact of the glycemic status on CAC progression after adjusting the variables with $\mathrm{p}<0.05$ in the univariate analysis. All statistical analyses were performed using the Statistical Package for the Social Sciences version 19 (SPSS, Chicago, Illinois), and a $\mathrm{p}$ value of $<0.05$ was considered significant for all analyses.

\section{Results}

\section{Baseline characteristics}

The mean age of participants was $52 \pm 9$ years, and a total of $10,472(84 \%)$ participants were males. Among them, 6578 (52.9\%), 4146 (33.3\%), and 1717 (13.8\%) were categorized in normal, pre-diabetes, and diabetes groups, respectively. Table 1 describes the baseline characteristics of participants based on their glycemic status. The clinical characteristics such as age, anthropometric indices, including body mass index and waist circumference, and the incidence of hypertension, dyslipidemia, and smoking were significantly different among all groups.

\section{CAC changes based on the glycemic status}

Table 2 presents the baseline and follow-up CAC scores based on the glycemic status. The average inter-scan period was $3.3 \pm 1.8$ years. The baseline and follow-up CAC scores based on glycemic status were significantly different ( $\mathrm{p}<0.001$ for all). The incidence of CAC progression was significantly different among the three groups (normal, 26.3\%; pre-diabetes, 30.9\%; diabetes, $46.9 \% ; \mathrm{p}<0.001$ ). Both the $\Delta \sqrt{ }$ transformed CAC (normal, $2.1 \pm 4.4$; pre-diabetes, $2.3 \pm 4.3$; diabetes, $4.0 \pm 6.5$; $\mathrm{p}<0.001$ ) and the annualized $\Delta \sqrt{ }$ transformed CAC (normal, $0.5 \pm 1.6$; pre-diabetes, $0.7 \pm 1.6$; diabetes, $1.2 \pm 2.4$; $\mathrm{p}<0.001)$ scores were different among the three groups. The diabetes group had higher $\Delta \sqrt{ }$ transformed CAC and annualized $\Delta \sqrt{ }$ transformed $C A C$ scores than the prediabetes and normal groups ( $\mathrm{p}<0.05$, respectively). The $\Delta \sqrt{ }$ transformed $C A C$ between normal and pre-diabetes groups were not significantly different. However, the prediabetes group had higher annualized $\Delta \sqrt{ }$ transformed CAC values than the normal group (Fig. 1).

\section{Association between clinical factors and CAC progression}

Univariate logistic regression analysis showed that age (odds ratio [OR] 1.070; 95\% confidential interval [CI ] 1.065-1.076), male gender (OR 2.650; 95\% CI 2.334-3.010), body mass index (OR 1.093; 95\% CI 1.078-1.108), hypertension (OR 2.091; 95\% CI 1.9302.266), dyslipidemia (OR 1.738; 95\% CI 1.600-1.887), smoking (OR 1.718; 95\% CI 1.571-1.879), and baseline CAC score > 100 (OR 2.818; 95\% CI 2.510-3.164) were 
Table 1 Baseline characteristics

\begin{tabular}{|c|c|c|c|c|}
\hline & Normal $(n=6578)$ & Pre-diabetes $(n=4146)$ & Diabetes $(n=1717)$ & $\mathrm{p}$ \\
\hline Age, years & $50 \pm 8$ & $53 \pm 8^{*}$ & $55 \pm 9^{* \dagger}$ & $<0.001$ \\
\hline Male, n (\%) & $5423(82.4)$ & $3523(85.0)$ & $1526(88.9)$ & $<0.001$ \\
\hline Body mass index, $\mathrm{kg} / \mathrm{m}^{2}$ & $24.1 \pm 2.6$ & $25.0 \pm 2.8^{*}$ & $25.2 \pm 2.9^{* \dagger}$ & $<0.001$ \\
\hline Waist circumference, $\mathrm{cm}$ & $85 \pm 8$ & $88 \pm 8^{*}$ & $89 \pm 8^{* \dagger}$ & $<0.001$ \\
\hline Systolic blood pressure, $\mathrm{mmHg}$ & $118 \pm 15$ & $122 \pm 15^{*}$ & $122 \pm 16^{*}$ & $<0.001$ \\
\hline Diastolic blood pressure, $\mathrm{mmHg}$ & $74 \pm 11$ & $77 \pm 10^{*}$ & $76 \pm 10^{*}$ & $<0.001$ \\
\hline Hypertension, n (\%) & $1568(24.4)$ & $1544(39.1)$ & $924(55.1)$ & $<0.001$ \\
\hline Antihypertensive drugs, n (\%) & $984(17.0)$ & $1077(30.2)$ & $675(43.2)$ & $<0.001$ \\
\hline Dyslipidemia, n (\%) & $1481(22.6)$ & $1286(31.0)$ & $701(40.8)$ & $<0.001$ \\
\hline Lipid lowering drugs, n (\%) & $89(4.2)$ & $143(10.8)$ & $76(18.8)$ & $<0.001$ \\
\hline Smoking, n (\%) & 3919 (64.4) & $2552(68.8)$ & $1166(74.0)$ & $<0.001$ \\
\hline Total cholesterol, mg/dL & $196 \pm 33$ & $203 \pm 34^{*}$ & $190 \pm 36^{* \dagger}$ & $<0.001$ \\
\hline Triglyceride, mg/dL & $130 \pm 79$ & $153 \pm 96^{*}$ & $156 \pm 102^{*}$ & $<0.001$ \\
\hline HDL cholesterol, mg/dL & $54 \pm 16$ & $53 \pm 16^{*}$ & $51 \pm 16^{* \dagger}$ & $<0.001$ \\
\hline LDL cholesterol, mg/dL & $122 \pm 31$ & $125 \pm 33^{*}$ & $115 \pm 33^{* \dagger}$ & $<0.001$ \\
\hline Creatinine, mg/dL & $0.9 \pm 0.2$ & $1.0 \pm 0.2$ & $1.0 \pm 0.2$ & 0.096 \\
\hline hs-CRP, mg/dL & $0.3 \pm 1.5$ & $0.4 \pm 2.1$ & $0.3 \pm 1.7$ & 0.086 \\
\hline Fasting glucose, mg/dL & $88 \pm 7$ & $100 \pm 10^{*}$ & $129 \pm 35^{* \dagger}$ & $<0.001$ \\
\hline $\mathrm{HbA} 1 \mathrm{C}, \%$ & $5.3 \pm 0.3$ & $5.7 \pm 0.3^{*}$ & $6.8 \pm 1.1^{* \dagger}$ & $<0.001$ \\
\hline
\end{tabular}

Values are given as mean \pm standard deviation or number (\%)

$H D L$ high-density lipoprotein, $h s-C R P$ high-sensitivity C-reactive protein, $L D L$ low-density lipoprotein

${ }^{*} \mathrm{p}<0.05$ vs. normal, ${ }^{\dagger} \mathrm{p}<0.05$ vs. pre-diabetes

Table 2 Progression of CAC based on the glycemic status

\begin{tabular}{llll}
\hline & Normal $(\mathbf{n}=\mathbf{6 5 7 8})$ & Pre-diabetes $(\mathbf{n}=\mathbf{4 1 4 6})$ & Diabetes $(\mathbf{n}=\mathbf{1 7 1 7})$ \\
\hline $\begin{array}{l}\text { Baseline } \\
\text { CAC score }\end{array}$ & & $\mathbf{p}$ \\
Categorical CAC score & $28 \pm 110$ & $49 \pm 158^{*}$ & $110 \pm 319^{* \dagger}$ \\
0 & $4308(65.5)$ & $2109(50.9)$ & $554(32.3)$ \\
$1-10$ & $840(12.8)$ & $608(14.7)$ & $286(16.7)$ \\
$11-100$ & $1002(15.2)$ & $924(22.3)$ & $490(28.5)$ \\
$101-400$ & $324(4.9)$ & $407(9.8)$ & $266(15.5)$ \\
$>400$ & $104(1.6)$ & $98(2.4)$ & $121(7.0)$ \\
Follow-up & & & $220 \pm 0.001$ \\
CAC score & $71 \pm 209$ & $97 \pm 235^{*}$ & \\
Categorical CAC score & & & $411(23.9)$ \\
0 & $3657(55.6)$ & $1732(41.8)$ & $122(7.1)$ \\
$1-10$ & $550(8.4)$ & $390(9.4)$ & $491(28.6)$ \\
$11-100$ & $1321(20.1)$ & $1048(25.3)$ & $410(23.9)$ \\
$101-400$ & $751(11.4)$ & $712(17.2)$ & $283(16.5)$ \\
$>400$ & $299(4.5)$ & $264(6.4)$ & $3.0(2.0-4.3)$
\end{tabular}

CAC coronary artery calcium

${ }^{*} \mathrm{p}<0.05$ vs. normal, ${ }^{\dagger} \mathrm{p}<0.05$ vs. pre-diabetes 


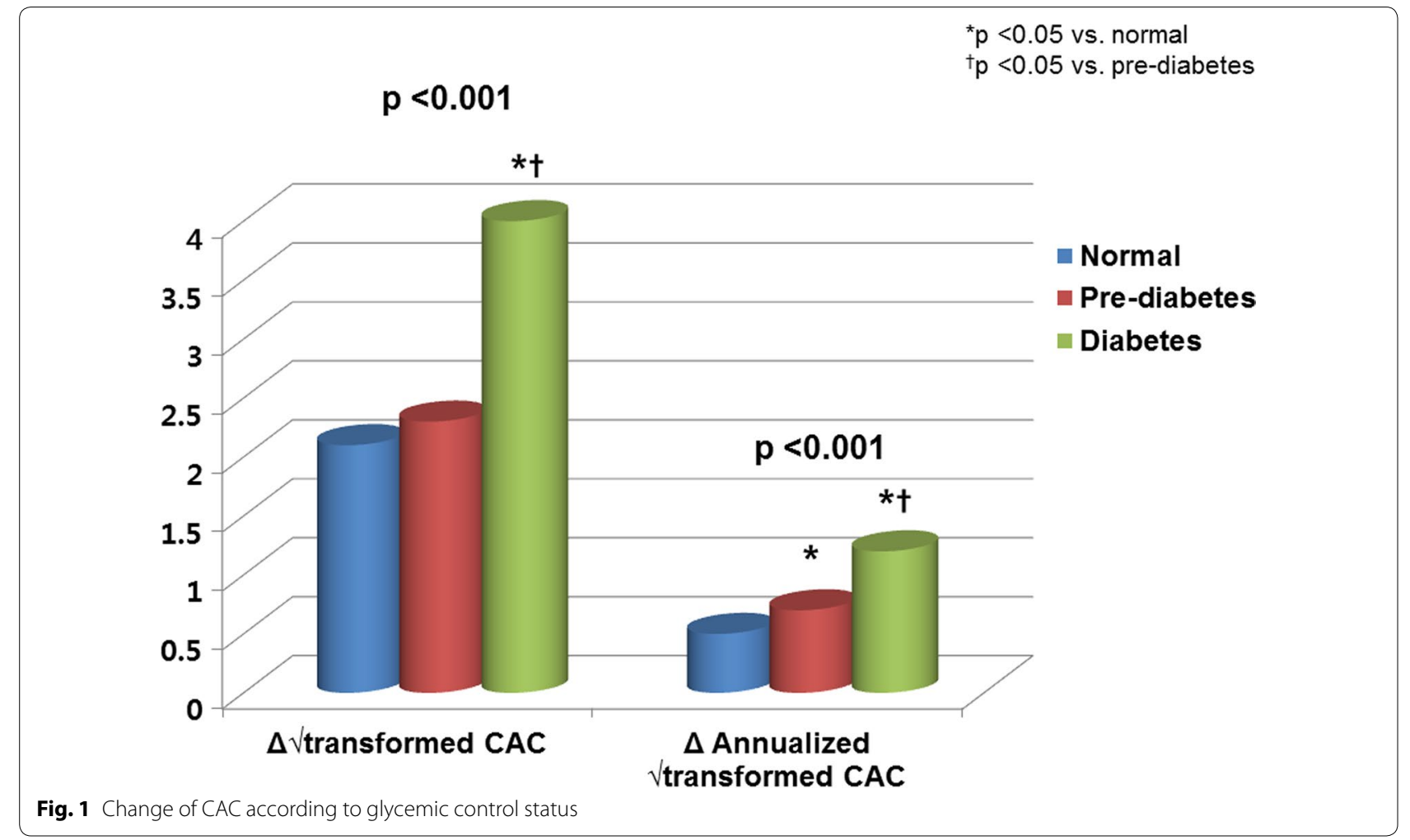

significantly associated with CAC progression $(\mathrm{p}<0.001$, respectively). Compared with the normal group, the subjects in the pre-diabetes (OR 1.253; 95\% CI 1.150-1.366) and diabetes (OR 2.471; 95\% CI 2.215-2.758) groups had an increased risk of CAC progression $(\mathrm{p}<0.001$, respectively). Multivariate logistic regression analysis showed that age (OR 1.069; 95\% CI 1.063-1.075), male gender (OR 2.422; 95\% CI 2.056-2.853), body mass index (OR 1.061; 95\% CI 1.043-1.079), hypertension (OR 1.364; 95\% CI 1.243-1.498), dyslipidemia (OR 1.464; 95\% CI 1.335-1.606), smoking (OR 1.386; 95\% CI 1.247-1.540), and baseline CAC score > 100 (OR 1.321; 95\% CI 1.1531.513) were significantly associated with $C A C$ progression ( $\mathrm{p}<0.001$, respectively). Compared with the normal group, the risk of CAC progression was not significantly different in pre-diabetes group (OR 0.943; 95\% CI $0.856-$ 1.040), but was significantly higher in the diabetes group (OR 1.368; 95\% CI 1.206-1.553) (Table 3).

\section{Independent predictors for CAC progression according to glycemic status}

The results of multivariate logistic regression analysis to identify the independent predictors for CAC progression according to glycemic status are presented in Table 4. In
Table 3 Logistic regression models to identify independent predictors of CAC progression

\begin{tabular}{|c|c|c|c|c|}
\hline \multirow[t]{2}{*}{ Variables } & \multicolumn{2}{|l|}{ Univariate } & \multicolumn{2}{|l|}{ Multivariate } \\
\hline & OR $(95 \% \mathrm{Cl})$ & $p$ & OR $(95 \% \mathrm{Cl})$ & $\mathrm{p}$ \\
\hline Age, years & $\begin{array}{l}1.070(1.065- \\
1.076)\end{array}$ & $<0.001$ & $\begin{array}{l}1.069(1.063- \\
1.075)\end{array}$ & $<0.001$ \\
\hline Male gender & $\begin{array}{l}2.650(2.334- \\
3.010)\end{array}$ & $<0.001$ & $\begin{array}{l}2.422(2.056- \\
2.853)\end{array}$ & $<0.001$ \\
\hline $\begin{array}{l}\text { Body mass } \\
\text { index, } \mathrm{kg} / \mathrm{m}^{2}\end{array}$ & $\begin{array}{l}1.093(1.078- \\
1.108)\end{array}$ & $<0.001$ & $\begin{array}{l}1.061(1.043- \\
1.079)\end{array}$ & $<0.001$ \\
\hline Hypertension & $\begin{array}{l}2.091(1.930- \\
2.266)\end{array}$ & $<0.001$ & $\begin{array}{l}1.364(1.243- \\
1.498)\end{array}$ & $<0.001$ \\
\hline Dyslipidemia & $\begin{array}{l}1.738(1.600- \\
1.887)\end{array}$ & $<0.001$ & $\begin{array}{l}1.464(1.335- \\
1.606)\end{array}$ & $<0.001$ \\
\hline Smoking & $\begin{array}{l}1.718(1.571- \\
1.879)\end{array}$ & $<0.001$ & $\begin{array}{l}1.386(1.247- \\
1.540)\end{array}$ & $<0.001$ \\
\hline $\begin{array}{r}\text { Baseline CAC } \\
\text { score }>100\end{array}$ & $\begin{array}{l}2.818(2.510- \\
3.164)\end{array}$ & $<0.001$ & $\begin{array}{l}1.321(1.153- \\
1.513)\end{array}$ & $<0.001$ \\
\hline \multicolumn{5}{|l|}{ Glycemic status } \\
\hline Normal & 1 & - & 1 & - \\
\hline Pre-diabetes & $\begin{array}{l}1.253(1.150- \\
1.366)\end{array}$ & $<0.001$ & $\begin{array}{l}0.943(0.856- \\
1.040)\end{array}$ & 0.241 \\
\hline Diabetes & $\begin{array}{l}2.471(2.215- \\
2.758)\end{array}$ & $<0.001$ & $\begin{array}{l}1.368(1.206- \\
1.553)\end{array}$ & $<0.001$ \\
\hline
\end{tabular}

$C A C$ coronary artery calcium, $\mathrm{Cl}$ confidence interval, $O R$ odds ratio 
Table 4 Independent predictors for CAC progression according to glycemic status

\begin{tabular}{|c|c|c|c|c|c|c|}
\hline \multirow[t]{2}{*}{ Variables } & \multicolumn{2}{|l|}{ Normal } & \multicolumn{2}{|l|}{ Pre-diabetes } & \multicolumn{2}{|l|}{ Diabetes } \\
\hline & OR $(95 \% \mathrm{Cl})$ & $p$ & OR $(95 \% \mathrm{Cl})$ & p & OR $(95 \% \mathrm{Cl})$ & $\mathbf{p}$ \\
\hline Age, years & $1.090(1.080-1.099)$ & $<0.001$ & $1.057(1.047-1.068)$ & $<0.001$ & $1.036(1.022-1.050)$ & $<0.001$ \\
\hline Male gender & $2.447(1.921-3.118)$ & $<0.001$ & $2.450(1.857-3.231)$ & $<0.001$ & 1.895 (1.279-2.810) & 0.001 \\
\hline Body mass index, $\mathrm{kg} / \mathrm{m}^{2}$ & $1.073(1.045-1.102)$ & $<0.001$ & $1.051(1.022-1.081)$ & $<0.001$ & $1.035(0.997-1.074)$ & 0.069 \\
\hline Hypertension & $1.478(1.284-1.701)$ & $<0.001$ & $1.552(1.332-1.808)$ & $<0.001$ & $0.910(0.732-1.131)$ & 0.395 \\
\hline Dyslipidemia & $1.658(1.443-1.905)$ & $<0.001$ & $1.590(1.365-1.853)$ & $<0.001$ & $0.980(0.794-1.209)$ & 0.849 \\
\hline Smoking & $1.463(1.256-1.703)$ & $<0.001$ & $1.385(1.155-1.660)$ & $<0.001$ & $1.170(0.900-1.523)$ & 0.241 \\
\hline Baseline CAC score > 100 & $1.685(1.333-2.131)$ & $<0.001$ & $1.212(0.974-1.508)$ & 0.085 & $1.286(0.994-1.663)$ & 0.056 \\
\hline
\end{tabular}

$C A C$ coronary artery calcium, $\mathrm{Cl}$ confidence interval, $\mathrm{OR}$ odds ratio

the normal group, age, male gender, body mass index, hypertension, dyslipidemia, smoking, and baseline CAC score $>100$ were significantly associated with CAC progression. All factors, except baseline CAC score $>100$, were also associated with CAC progression in the prediabetes group. However, only age and male gender were independent predictors of CAC progression in the diabetes group.

\section{Discussion}

The main finding of this longitudinal study is that diabetes has an independent impact on CAC progression; however, pre-diabetes is not associated with CAC progression after adjusting for confounding clinical factors in asymptomatic subjects.

Coronary artery calcification is an important marker to identify the presence of CAD in asymptomatic subjects. It is a well-known and useful tool to predict adverse clinical events [7-10]. Previous cross-sectional studies reported the significant risk factors for CAC [16-18].

Recently, the emphasis has been on identifying CAC progression in clinical practice because of its increasing value in predicting adverse outcomes over the baseline CAC score, time between scans, demographics, and CV risk factors [11]. Several previous studies have investigated the predictive value of clinical factors for CAC progression. In the Heinz Nixdorf Recall study, CAC inevitably progressed with limited influence of $\mathrm{CV}$ risk factors [19]. Diederichsen et al. [20] recently evaluated the predictive value of 15 biomarkers for CAC incidence and progression in asymptomatic middle-aged subjects at 5 years follow-up. This prospective study identified the association between total and LDL cholesterol and CAC incidence, and between phosphate and CAC progression; however, 12 other biomarkers did not significantly correlate with CAC. Nevertheless, the impact of glycemic status, especially in a pre-diabetic condition, on CAC progression in asymptomatic individuals has remained uncertain.

In the Multi-Ethnic Study of Atherosclerosis (MESA) study, diabetes had the strongest impact on CAC progression in Black, and the weakest in Hispanic people, with intermediate associations in White and Chinese people [21]. Furthermore, Wong et al. [22] reported that subjects with metabolic syndrome (MetS) and diabetes had a greater $\mathrm{CAC}$ incidence and absolute progression compared with those without these conditions. However, the proportion of Asian participants in the study was small, and the association between pre-diabetes and CAC progression was not evaluated in the MESA study. Other studies have evaluated the relationship between prediabetes and the risk of CAD; however, the results were inconsistent $[5,23]$.

Recently, a large observational study reported that pre-diabetes was not associated with an increased risk of subclinical coronary atherosclerosis in an asymptomatic Korean population [24]. However, this study did not evaluate the atherosclerotic progression because of its cross-sectional design. The result of the present study is consistent in that pre-diabetes did not have an independent impact on CAC progression. Contrary to these results, Lee et al. [25] reported that MetS influenced the progression of $\mathrm{CAD}$ as assessed by CAC scores and coronary CT angiography in a relatively healthy Korean population. However, this study included established diabetes in the definition of MetS. Considering that the World Health Organization recommends that the concept of MetS should not be applied in subjects with established diabetes [26], pre-diabetes is different from MetS in subjects without established diabetes. Thus, the emphasis should not only be on controlling concomitant metabolic risk factors but also on preventing the development of diabetes to inhibit CAC progression in asymptomatic pre-diabetics in clinical practice. 
The present study identified that diabetes was associated with an increased risk of CAC progression after adjusting for confounding factors. It is well-known that vascular calcification is increased in diabetes, and the presence of $\mathrm{CAC}$ is a strong risk factor for $\mathrm{CV}$ events [27]. One of the most important mechanisms in diabetes patients was hyperglycemic damage, mainly driven by the accumulation of free radicals, which activates vascular inflammation and endothelial dysfunction. In addition, hyperglycemia itself also increases oxidative stress by increasing glucose oxidation [28]. Previous studies strongly suggested that hyperglycemia may directly influence the atherosclerotic process and prognosis in established diabetes patients [29-33]. In contrast, several studies reported that MetS does not significantly influence subclinical atherosclerosis and mortality in relatively healthy diabetes patients $[34,35]$. In the present study, we observed that traditional CV risk factors, such as hypertension, dyslipidemia, and smoking, were independent determinants for CAC progression in both normal and pre-diabetes, but were not associated with CAC progression in diabetes patients. Thus, strict glycemic control may be more important to prevent future $\mathrm{CV}$ events in asymptomatic subjects with diabetes than traditional risk factors. Further investigation to identify the impact of strict glycemic control on CAC progression and prognosis is necessary in asymptomatic patients with established diabetes.

Although multiple imaging techniques are available to detect the presence of pre-clinical disease, the efficacy of these modalities in the risk stratification of asymptomatic diabetes patients remains uncertain. Recently, Rassi et al. [36] reported that CAC was the most accurate screening modality for detection of CAD, but that screening for carotid plaque using normal coronary $\mathrm{CT}$ angiography may better characterize stroke risk in asymptomatic diabetics. However, this study was performed in only 98 participants. Further prospective studies with larger sample sizes are required to address this issue.

The present study has several limitations. First, the KOICA registry was based on a healthy population who underwent health checkups in healthcare centers, which may result in a potential selection bias. Second, this was a retrospective study, which may be influenced by unidentified confounders. Third, participants did not undergo an oral glucose tolerance test; however, FPG is proven to be a useful parameter in clinical practice [37]. Fourth, data on the physical activity of participants were unavailable. However, this study was performed on asymptomatic subjects in a self-referral setting. Fifth, we could not eliminate the possible effects of medications for hypertension, dyslipidemia, and diabetes on the progression of CAC because of the observational design. Further large prospective studies are necessary to address these issues. Finally, the present study included the Korean population only. However, this longitudinal study uniquely identified the CAC progression based on the glycemic status in asymptomatic individuals, specifically in the Asian population.

\section{Conclusion}

In conclusion, diabetes had an incremental effect on CAC progression; however, pre-diabetes was not associated with an increased risk of CAC progression after adjusting for confounding factors in asymptomatic subjects.

\section{Abbreviations \\ CAC: coronary artery calcification; CAD: coronary artery disease; Cl: confidence interval; $\mathrm{CT}$ : computed tomography; FPG: fasting plasma glucose; $\mathrm{HbA} 1 \mathrm{c}$ : hemoglobin A1c; HDL: high-density lipoprotein; KOICA: Korea Initiatives on Coronary Artery Calcification; LDL: low-density lipoprotein; MESA: Multi-Ethnic Study of Atherosclerosis; OR: odds ratio.}

\section{Authors' contributions}

All authors have made substantial contributions. KW and JMS performed the statistical analysis. KW drafted the manuscript. $\mathrm{DH}, \mathrm{JHL}$, and SL supervised the data analysis and manuscript drafting. SC, EJC, SHP, HH, JS, HOJ, and HC contributed to data acquisition. $\mathrm{KW}, \mathrm{JMS}$, and $\mathrm{HC}$ contributed to the interpretation of data. $\mathrm{HC}$ critically revised the manuscript. All authors read and approved the final manuscript.

\section{Author details \\ ${ }^{1}$ Division of Cardiology, Ulsan University Hospital, University of Ulsan College of Medicine, Ulsan, South Korea. ${ }^{2}$ Division of Cardiology, Yonsei Cardiovas- cular Center, Yonsei University Health System, Seoul, South Korea. ${ }^{3}$ Division of Cardiology, Healthcare System Gangnam Center, Seoul National University Hospital, Seoul, South Korea. ${ }^{4}$ Division of Radiology, Seoul National University Bundang Hospital, Seongnam, South Korea. ${ }^{5}$ Division of Radiology, Gangnam Heartscan Clinic, Seoul, South Korea. ${ }^{6}$ Department of Internal Medicine, Gangnam Heartscan Clinic, Seoul, South Korea. ${ }^{7}$ Division of Cardiology, Heart Stroke \& Vascular Institute, Samsung Medical Center, Seoul, South Korea. ${ }^{8}$ Divi- sion of Cardiology, Department of Internal Medicine, College of Medicine, Seoul St. Mary's Hospital, The Catholic University of Korea, Seoul, South Korea. \\ ${ }^{9}$ Division of Cardiology, Severance Cardiovascular Hospital, Yonsei Univer- sity College of Medicine, Yonsei University Health System, 50-1 Yonsei-ro, Seodaemun-gu, Seoul 03722, South Korea.}

\section{Acknowledgements}

This work was supported by a Grant from the Korean Health Technology R\&D Project, Ministry of Health and Welfare, Republic of Korea (HI13C0715).

\section{Competing interests}

The authors declare that they have no competing interests.

\section{Availability of data and materials}

The datasets used and analyzed during the current study are available from the corresponding author on reasonable request.

\section{Consent for publication}

Not applicable.

Ethics approval and consent to participate

Due to the retrospective nature of this study, IRB waived the need for written informed consent from the participants.

Funding

Not applicable. 


\section{Publisher's Note}

Springer Nature remains neutral with regard to jurisdictional claims in published maps and institutional affiliations.

Received: 25 September 2017 Accepted: 23 December 2017 Published online: 04 January 2018

\section{References}

1. Lee WL, Cheung AM, Cape D, Zinman B. Impact of diabetes on coronary artery disease in women and men: a meta-analysis of prospective studies. Diabetes Care. 2000;23:962-8.

2. Kanaya AM, Grady D, Barrett-Connor E. Explaining the sex difference in coronary heart disease mortality among patients with type 2 diabetes mellitus: a meta-analysis. Arch Intern Med. 2002;162:1737-45.

3. Huxley R, Woodward M, Barzi F, Wong JW, Pan WH, Patel A. Does sex matter in the associations between classic risk factors and fatal coronary heart disease in populations from the Asia-Pacific region? J Womens Health (Larchmt). 2005;14:820-8.

4. Huxley R, Barzi F, Woodward M. Excess risk of fatal coronary heart disease associated with diabetes in men and women: meta-analysis of 37 prospective cohort studies. BMJ. 2006;332:73-8.

5. Pankow JS, Kwan DK, Duncan BB, Schmidt MI, Couper DJ, Golden S, et al. Cardiometabolic risk in impaired fasting glucose and impaired glucose tolerance: the Atherosclerosis Risk in Communities Study. Diabetes Care. 2007;30:325-31.

6. Carson AP, Steffes MW, Carr JJ, Kim Y, Gross MD, Carnethon MR, et al. Hemoglobin a1c and the progression of coronary artery calcification among adults without diabetes. Diabetes Care. 2015;38:66-71.

7. Arad Y, Spadaro LA, Goodman K, Newstein D, Guerci AD. Prediction of coronary events with electron beam computed tomography. J Am Coll Cardiol. 2000;36:1253-60.

8. Wong ND, Hsu JC, Detrano RC, Diamond G, Eisenberg H, Gardin JM. Coronary artery calcium evaluation by electron beam computed tomography and its relation to new cardiovascular events. Am J Cardiol. 2000;86:495-8

9. Budoff MJ, Shaw LJ, Liu ST, Weinstein SR, Mosler TP, Tseng PH, et al. Longterm prognosis associated with coronary calcification: observations from a registry of 25,253 patients. J Am Coll Cardiol. 2007:49:1860-70.

10. Detrano R, Guerci AD, Carr JJ, Bild DE, Burke G, Folsom AR, et al. Coronary calcium as a predictor of coronary events in four racial or ethnic groups. N Engl J Med. 2008;358:1336-45.

11. Budoff MJ, Hokanson JE, Nasir K, Shaw LJ, Kinney GL, Chow D, et al. Progression of coronary artery calcium predicts all-cause mortality. JACC Cardiovasc Imaging. 2010;3:1229-36.

12. American Diabetes Association. Standards of medical care in diabetes-2014. Diabetes Care. 2014;37(Suppl. 1):S14-80.

13. Furusyo N, Koga T, Ai M, Otokozawa S, Kohzuma T, Ikezaki H, et al. Utility of glycated albumin for the diagnosis of diabetes mellitus in a Japanese population study: results from the Kyushu and Okinawa Population Study (KOPS). Diabetologia. 2011;54:3028-36.

14. Agatston AS, Janowitz WR, Hildner FJ, Zusmer NR Jr, Viamonte M, Detrano R. Quantification of coronary artery calcium using ultrafast computed tomography. J Am Coll Cardiol. 1990;15:827-32.

15. Hokanson JE, MacKenzie T, Kinney G, Snell-Bergeon JK, Dabelea D, Ehrlich J, et al. Evaluating changes in coronary artery calcium: an analytical approach that accounts for interscan variability. AJR Am J Roentgenol. 2004;182:1327-32.

16. Kim MK, Ahn CW, Kang S, Nam JS, Kim KR, Park JS. Relationship between the triglyceride glucose index and coronary artery calcification in Korean adults. Cardiovasc Diabetol. 2017;16:108

17. Sung KC, Chang Y, Ryu S, Chung HK. High levels of serum vitamin D are associated with a decreased risk of metabolic diseases in both men and women, but an increased risk for coronary artery calcification in Korean men. Cardiovasc Diabetol. 2016;15:112.

18. Russo D, Morrone LF, Imbriaco M, Pota A, Russo L, Scognamiglio B, et al. Coronary artery calcification and outcomes in diabetic patients with and without chronic kidney disease. Blood Purif. 2013;36:17-20.
19. Erbel R, Lehmann N, Churzidse S, Rauwolf M, Mahabadi AA, Möhlenkamp $\mathrm{S}$, et al. Progression of coronary artery calcification seems to be inevitable, but predictable-results of the Heinz Nixdorf Recall (HNR) study. Eur Heart J. 2014;35:2960-71.

20. Diederichsen SZ, Grønhøj MH, Mickley H, Gerke O, Steffensen FH, Lambrechtsen J, et al. CT-detected growth of coronary artery calcification in asymptomatic middle-aged subjects and association with 15 biomarkers. JACC Cardiovasc Imaging. 2017; 10:858-66.

21. Kronmal RA, McClelland RL, Detrano R, Shea S, Lima JA, Cushman M, et al. Risk factors for the progression of coronary artery calcification in asymptomatic subjects: results from the Multi-Ethnic Study of Atherosclerosis (MESA). Circulation. 2007;115:2722-30.

22. Wong ND, Nelson JC, Granston T, Bertoni AG, Blumenthal RS, Carr JJ, et al. Metabolic syndrome, diabetes, and incidence and progression of coronary calcium: the Multiethnic Study of Atherosclerosis study. JACC Cardiovasc Imaging. 2012;5:358-66.

23. Levitzky YS, Pencina MJ, D'Agostino RB, Meigs JB, Murabito JM, Vasan RS, et al. Impact of impaired fasting glucose on cardiovascular disease: the Framingham Heart Study. J Am Coll Cardiol. 2008;51:264-70.

24. Park GM, Cho YR, Lee SW, Yun SC, Won KB, Ann SH, et al. Prediabetes is not a risk factor for subclinical coronary atherosclerosis. Int J Cardiol. 2017:243:479-84.

25. Kim LK, Yoon JW, Lee DH, Kim KM, Choi SH, Park KS, et al. Impact of metabolic syndrome on the progression of coronary calcium and of coronary artery disease assessed by repeated cardiac computed tomography scans. Cardiovasc Diabetol. 2016;15:92

26. Simmons RK, Alberti KG, Gale EA, Colagiuri S, Tuomilehto J, Qiao Q, et al. The metabolic syndrome: useful concept or clinical tool? Report of a WHO expert consultation. Diabetologia. 2010;53:600-5.

27. Snell-Bergeon JK, Budoff MJ, Hokanson JE. Vascular calcification in diabetes: mechanisms and implications. Curr Diabetes Rep. 2013;13:391-402.

28. Nishikawa T, Edelstein D, Du XL, et al. Normalizing mitochondrial superoxide production blocks three pathways of hyperglycaemic damage. Nature. 2000;404:787-90.

29. Larsen JR, Brekke M, Bergengen L, Sandvik L, Arnesen H, Hanssen KF, et al. Mean $\mathrm{HbA} 1 \mathrm{c}$ over 18 years predicts carotid intima media thickness in women with type 1 diabetes. Diabetologia. 2005;48:776-9.

30. Meigs JB, Larson MG, D'Agostino RB, Levy D, Clouse ME, Nathan DM, et al. Coronary artery calcification in type 2 diabetes and insulin resistance: the Framingham offspring study. Diabetes Care. 2002;25:1313-9.

31. Sander D, Schulze-Horn C, Bickel H, Gnahn H, Bartels E, Conrad B. Combined effects of hemoglobin A1C and C-reactive protein on the progression of subclinical carotid atherosclerosis: the INVADE study. Stroke. 2006;37:351-7.

32. Hayward RA, Reaven PD, Wiitala WL, Bahn GD, Reda DJ, Ge L, et al. Followup of glycemic control and cardiovascular outcomes in type 2 diabetes. N Engl J Med. 2015;372:2197-206.

33. Orchard TJ, Nathan DM, Zinman B, Cleary P, Brillon D, Backlund JY, et al. Association between 7 years of intensive treatment of type 1 diabetes and long-term mortality. JAMA. 2015;313:45-53.

34. Won KB, Chang HJ, Kim HC, Jeon K, Lee H, Shin S, et al. Differential impact of metabolic syndrome on subclinical atherosclerosis according to the presence of diabetes. Cardiovasc Diabetol. 2013:12:41.

35. Won KB, Chang HJ, Han D, Sung J, Choi SY. Metabolic syndrome predicts long-term mortality in subjects without established diabetes mellitus in asymptomatic Korean population: a propensity score matching analysis from the Korea Initiatives on Coronary Artery Calcification (KOICA) registry. Medicine (Baltimore). 2016;95:e5421.

36. Rassi CH, Churchill TW, Tavares CA, Fahel MG, Rassi FP, Uchida AH, et al. Use of imaging and clinical data to screen for cardiovascular disease in asymptomatic diabetics. Cardiovasc Diabetol. 2016;15:28.

37. Nasir K, Santos RD, Tufail K, Rivera J, Carvalho JA, Meneghello R, et al. High-normal fasting blood glucose in non-diabetic range is associated with increased coronary artery calcium burden in asymptomatic men. Atherosclerosis. 2007;195:e155-60. 